\title{
An assessment of the FlowCapt acoustic sensor for measuring snowdrift in the Indian Himalayas
}

\author{
R K DAS*, P DATT and A ACHARYA \\ Snow and Avalanche Study Establishment (SASE), Sector-37A, Chandigarh 160 036, India. \\ ${ }^{*}$ Corresponding author. e-mail: rk.das@sase.drdo.in
}

\begin{abstract}
Wind caused snow drifting plays a dominant role in the redistribution of snow mass that restructures a snowpack. Strong wind activity at the mountain tops results in uneven distribution of snow with erosion on windward side and deposition on leeward areas. Such snowdrift events are responsible for the formation of cornices, increase in the loading of avalanche release zones on the leeward side and consequent increase in the level of avalanche hazard. In this paper, we present the results of snowdrift measurement using an acoustic snow-drift meter, the FlowCapt, built by IAV Engineering, which was used during winter seasons of 2007-2010 at a field research station of Snow and Avalanche Study Establishment (SASE) in the western Himalayas. The aim of the study was to evaluate the suitability of the instrument in measuring snowdrift in the Himalayan weather conditions. Results proved the utility of the instrument as a useful tool to study drifting snow in remote areas. However, in the absence of conventional snow gauges for validation, the quality of the absolute snow flux data could not be ascertained.
\end{abstract}

\section{Introduction}

The snow mass transfer due to snowdrift plays a major role in the avalanche formation and mass balance of a snow cover. High wind activity in snow-bound mountainous areas in the winter generally creates instability in the snowpack. Cornices formed on the leeward side of the ridge-tops due to drifting snow become extremely hazardous as they tend to break and trigger avalanches covering larger areas. Amount of snow drifted from the windward side and accumulated on the leeward side is not only the function of wind conditions but it also depends on the nature of the snowpack too. The rate at which the snowpack is loaded in the avalanche release zone as a result of redistribution of snow due to snowdrift is an important parameter related to delayed action slab avalanche activities. Therefore, accurate measurement of snow loading in the avalanche release zones due to wind drift is vital for improving avalanche forecasts (Bolognesi 1996).

This study presents the analyses of 93 snowdrift events observed during three consecutive winters from 2007-2010 at D-10 field research station of SASE in the western Himalaya. A commercially available acoustic instrument, the FlowCapt, was used for recording the drift events. An attempt is made to interpret the results obtained from the analyses of the data vis-à-vis snow and meteorological parameters recorded during this period.

Keywords. Snowdrift; saltation; suspension; friction velocity; FlowCapt; cryosphere; data analysis. 


\section{Background}

Snow particles are transported by wind in three different drift processes (Bagnold 1941), viz., creep, saltation and suspension. Measurement of drift flux has been a major task and several devices have been developed over the years to measure this parameter and to quantify the drift phenomenon. Although it is possible to measure creep by monitoring the relative movement of buried traps in the snowpack, it is generally not considered in flux measurements due to the very small quantity of snow transported by this process. Also, it is difficult to measure the saltation process because of its shallow height of predominance at around $10.0 \mathrm{~cm}$ from the surface (Jaedicke 2001).

The oldest instruments used for measuring snowdrift are the snow traps. The traps slowdown the air carrying snow particles inside the trap and allow the particles to settle within the trap. Various forms of the snow trap have been designed for saltation and suspension layers over the years (Mellor 1960; Shiotani and Arai 1967). The Mellor trap, first introduced in 1960 (Mellor 1960) has been commonly used for many years. Filter instruments, similar to the trap, have also been constructed and used for measurement of snowdrift since the 1980's (Takeuchi 1980; Schmidt et al. 1984; Bolognesi 1996).

The snowdrift density and snow mass flux profiles are measured using these instruments by installing them at different ground levels. The major disadvantage of trap and filter type instruments is that they interfere with the flow of wind and reach their full measuring capacity in limited period of time which may range from a few hours to only few minutes depending upon the strength of the snowdrift episode. The measurement then needs to be stopped and the collected snow mass is quantified. This is an arduous task considering the harsh climate. Also, it is not possible to obtain instantaneous measurement values from these instruments and only timeaveraged results could be obtained (Chritin et al. 1999; Jaedicke 2001). These disadvantages of the traps and filters led to the development of alternative methods and instruments for snowdrift measurements. The first alternative instrument that was developed was the optical snowdrift measuring instrument (Sommerfeld and Businger 1965) which operated on the principle of attenuation of light and scintillations produced by drifting snow particles. Subsequently, snow particle counter was developed which counts the number of flowing snow particles (Schmidt 1977; Gubler 1981). A similar instrument developed by Schmidt (1977) could measure the speed and the size of the snow particles. Although these instruments did not obstruct the flow of wind, they needed frequent manual calibration and the optics of the instruments needed cleaning as they often got covered by snow.

\section{Instrument}

The FlowCapt acoustic sensor is designed for continuous and automatic recording of snowdrift events (Chritin et al. 1999; Chritin and Gubler 2005). The principle behind drift detection is primarily based on acousto-mechanical coupling. The sensor consists of segments of closed pipes of $1.0 \mathrm{~m}$ length inside which electro-acoustic transducers are placed along with a powering, filtering and amplifying unit. When the sensor is exposed to a flux of drifting snow particles, the particles strike the sensor pipes and produce acoustic pressure. The transducer picks up the signal whose intensity depends on the speed and the mass of the transported snow particles. The electrical outputs are then filtered and time-averaged in given frequency ranges to provide a signal proportional to particle flux Q $\left(\mathrm{gm}^{-2} \mathrm{~S}^{-1}\right)$ and logged in a datalogger. The instrument can be used to obtain information about the occurrence, the duration and the intensity of the flux of snow particles drifted by the wind. This information related to a snowdrift event of a given site is of great importance for operational avalanche forecasting because the major snowdrift events are most often associated with regional wind patterns (Brun et al. 1992).

\section{Field deployment}

In October 2007, a two-segment FlowCapt sensor was integrated to a standard Automatic Weather Station (AWS) near a ridge at D-10 Top field research station of SASE in the Pirpanjal Ranges at an altitude of $2850 \mathrm{~m}$ (a.s.l.) near Jawahar tunnel in the state of Jammu \& Kashmir, India. This site was selected for snowdrift study as it has a natural wind tunnel like terrain, and avalanches due to snowdrift are common in the area. The wind in the region blows mainly from the northeast and south-west directions. Table 1 depicts the percentage of time wind direction observed quadrantwise over the three consecutive winters (2007 to 2010). Wind gust as high as $23.37 \mathrm{~ms}^{-1}$ was observed during this period. The percentage of time wind speed observed within different wind speed ranges is given in table 2. A Campbell Scientific datalogger, model CR23X, was used to log data from the lower $(0-1 \mathrm{~m})$ and the upper (1-2 m) segments of the FlowCapt sensor as well as from an anemometer. Wind measurements were made using an RM Young propeller-vane type 
Table 1. Quadrantwise variation of wind direction.

\begin{tabular}{lcccc}
\hline Period & $\begin{array}{c}\text { Quad-I } \\
(\%)\end{array}$ & $\begin{array}{c}\text { Quad-II } \\
(\%)\end{array}$ & $\begin{array}{c}\text { Quad-III } \\
(\%)\end{array}$ & $\begin{array}{c}\text { Quad-IV } \\
(\%)\end{array}$ \\
\hline November 2007-April 2008 & 40.10 & 1.96 & 55.29 & 2.66 \\
November 2008-April 2009 & 38.29 & 0.81 & 58.90 & 2.00 \\
November 2009-February 2010 & 26.44 & 8.27 & 54.72 & 10.57 \\
\hline
\end{tabular}

Table 2. Percentage of time wind speed observed in different wind speed ranges.

\begin{tabular}{lccccc}
\hline & \multicolumn{5}{c}{$\% \mathrm{WS}$} \\
\cline { 2 - 6 } Period & $\begin{array}{c}(0-5) \\
\mathrm{ms}^{-1}\end{array}$ & $\begin{array}{c}(5-10) \\
\mathrm{ms}^{-1}\end{array}$ & $\begin{array}{c}(10-15) \\
\mathrm{ms}^{-1}\end{array}$ & $\begin{array}{c}(15-20) \\
\mathrm{ms}^{-1}\end{array}$ & $\begin{array}{c}>20 \\
\mathrm{~ms}^{-1}\end{array}$ \\
\hline November 2007-April 2008 & 29.15 & 44.78 & 22.71 & 3.19 & 0.16 \\
November 2008-April 2009 & 25.79 & 45.66 & 25.38 & 2.99 & 0.18 \\
November 2009-February 2010 & 28.55 & 44.13 & 22.33 & 4.94 & 0 \\
\hline
\end{tabular}

anemometer, model 05103, which was installed at a height of $6.0 \mathrm{~m}$ near the FlowCapt. The datalogger was programmed to sample snowdrift, wind speed and wind direction data at every 30 seconds and average values of drift and wind speed data and vector average of wind direction data were recorded every hour. The battery of the weather station was continually charged with solar panels for all-year stand-alone operation. The study area on panchromatic satellite image and the FlowCapt sensor after deployment are shown in figure 1 .

While collecting the field data, some major challenges were experienced. There were instances where the personnel, manning the research station had to attend to the AWS to clear off snow from the FlowCapt and the wind sensor. The database of the drift events indicated that there were 13 riming occasions when even the propeller-vane anemometer got stuck and showed no changes in its readings. The drift data recorded during such period were treated as erroneous and hence were not used in the study as it is possible that partial underestimation of the snowdrift might have occurred due to temporary loss of sensitivity on the two segments. The other source of missing data was the non-functionality of the AWS due to a discharged battery. The AWS could not be revived from February 2010 till rest of the winter as the charge controller of the AWS failed. The overall uptime percentage of the FlowCapt was approximately $87 \%$ for its period of deployment from November 2007 till April 2010.

\section{Results and discussions}

Snow drift activities occur in the study site during the entire winter season starting from November to the end of April. During the three winters, a total of 93 drift events were recorded successfully when the AWS along with the FlowCapt and the wind sensor

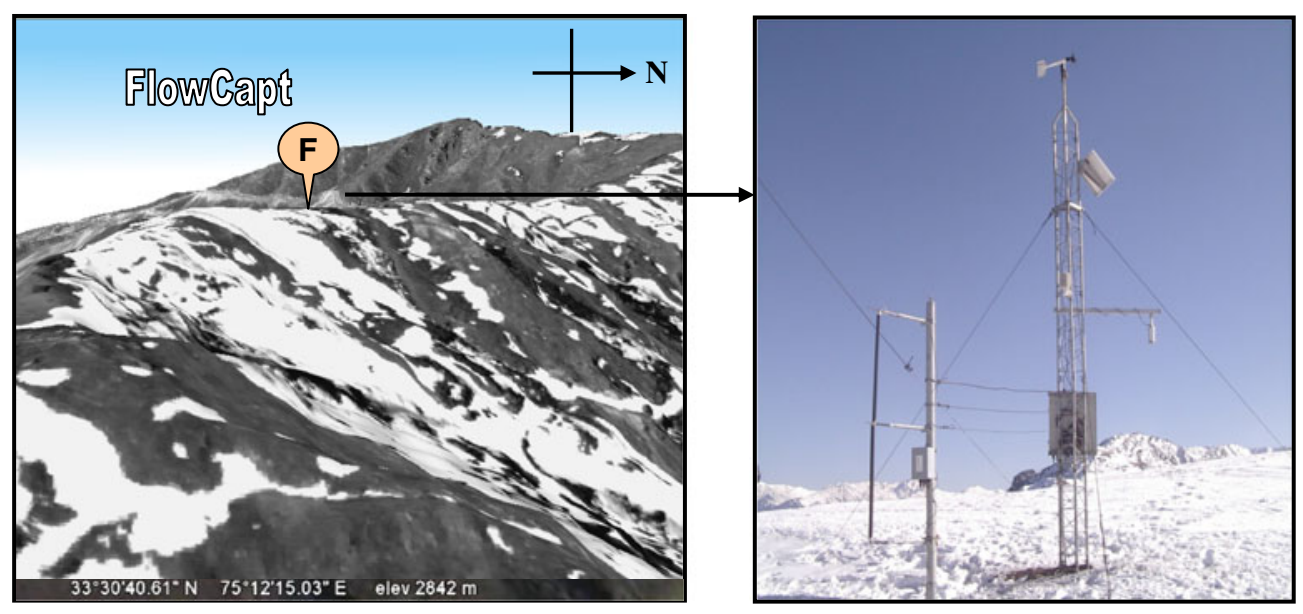

Figure 1. The FlowCapt sensor with the Automatic Weather Station at the D-10 Top research station. 
were working properly. To determine the applicability of the sensor in measuring snowdrift activity in the lower Himalayan regions (Sharma and Ganju 2000), the entire drift database for the three winters has been classified into 'snowfall-day' and 'no snowfall-day' drift events. The drift events which were accompanied by new snow fall were termed as 'snowfall-day events' and the drift events which occurred without new snow were termed as 'no snowfall-day events'. These drift events have been analysed and interpreted relative to other snowmet parameters. The results of the drift event analyses in tabular form are given in table 3 .

It can be observed from the table that 33 drift events were observed during snowfall-days and 60 events were observed during no snowfall-days. During snowfall-days, the snow was loose and very soft with average density of approximately $143 \mathrm{kgm}^{-3}$ which helped the wind to erode it from the surface with average threshold wind speed of $6.45 \mathrm{~ms}^{-1}$. The free fall ram penetrability of the snow surface decreased during no snowfall-days as a result of metamorphism and wind packing of snow with time. The average threshold wind velocity $\left(u_{\mathrm{th}}\right)$ and average threshold friction velocity $\left(u_{* \text { th }}\right)$ were observed to be higher in case of no snowfall-days as threshold velocities tend to increase for old, wind-packed or partly melted snow (Li and Pomeroy 1997). The average of $u_{* \text { th }}$ values for both snowfall-days as well as no snowfall-days was found varying between 0.26 and $0.35 \mathrm{~ms}^{-1}$. This agrees well with previously reported values by Pomeroy and Gray (1990). The average saltation height $(h)$ for all the drift events was observed to be only up to a few centimeters. These results are in good agreement with previously reported findings (Jaedicke 2001; Lieberherr 2010) that saltation is dominant at very shallow heights of about $10.0 \mathrm{~cm}$ from the surface.

Two snowdrift activities during January 2009 were arbitrarily selected from the drift database and have been analysed in the following sections as these events can be considered representative of the snowdrift events observed at the D-10 site during the study period. The hourly graphical representation of the average mass flux measured by each segment as well as average total flux of the acoustic snowdrift sensor are shown in figure 2 along with wind speed and wind direction.

\subsection{Snow mass flux}

Figure 2(a) depicts the hourly average snow mass flux as measured by the lower segment (FCFlux_1_Avg) for height $0-1 \mathrm{~m}$ and the hourly average snow mass flux as measured by the upper segment (FCFlux_2_Avg) for height 1-2 $\mathrm{m}$ of the FlowCapt sensor. It was observed that the lower segment recorded higher values than the upper segment in both the drift events. According to McClung and Schaerer (1993), approximately 90\% of snow transportation occurs due to snowdrift, of which, about $50-75 \%$ is contributed by saltation which remains predominant at very shallow height of about $10.0 \mathrm{~cm}$ from the surface. Theoretically, each snowdrift event is characterized by a higher intensity on the $0-1 \mathrm{~m}$ lower segment as compared to the 1-2 m upper segment (Chritin and Gubler 2005). However, pure blowing snow events may show similar intensity on both the segments or even higher intensity on the upper segment of the sensor.

Figure 2(c) depicts the hourly average of total snow mass flux which is the sum of the average flux of the lower and upper segments. This parameter can be used to calculate total snow mass transported and total mass of snow deposited on a potential avalanche release zone.

\subsection{Snowpack information}

The observatory located near the FlowCapt recorded $168 \mathrm{~cm}$ of fresh snow in two snow storm spells during the study period as shown in figure 3 . The average ambient temperature during this period was $-2.0^{\circ} \mathrm{C}$. The first snowdrift activity started around 0000 hrs on 20 January, soon after the first snow storm had subsided as shown in figure 2(a). The density of snow varied from 120 to $200 \mathrm{kgm}^{-3}$. Snow was eroded by wind from the surface with average wind speed of $14.40 \mathrm{~ms}^{-1}$ from the southwest direction (SASE Annual technical report

Table 3. Classification of snowdrift events from 2007-2010.

\begin{tabular}{|c|c|c|c|c|c|c|c|c|c|c|c|}
\hline Class & $\begin{array}{c}\text { No. of } \\
\text { drift } \\
\text { events }\end{array}$ & $\begin{array}{c}\text { Avg. } \\
u \\
\left(\mathrm{~ms}^{-1}\right)\end{array}$ & $\begin{array}{c}\operatorname{Max} \\
u \\
\left(\mathrm{~ms}^{-1}\right)\end{array}$ & $\begin{array}{c}\text { Avg. } \\
u_{\mathrm{th}} \\
\left(\mathrm{ms}^{-1}\right)\end{array}$ & $\begin{array}{c}\text { Avg. } \\
u_{* \operatorname{th}} \\
\left(\mathrm{ms}^{-1}\right)\end{array}$ & $\begin{array}{c}\text { Avg. } \\
\quad h \\
(\mathrm{~cm})\end{array}$ & $\begin{array}{c}\text { Avg. } \\
\text { AT } \\
\left({ }^{\circ} \mathrm{C}\right)\end{array}$ & $\begin{array}{l}\text { Avg. new } \\
\text { snow } \\
\text { height } \\
(\mathrm{cm})\end{array}$ & $\begin{array}{c}\text { Avg. new } \\
\text { snow } \\
\text { density } \\
\left(\mathrm{kgm}^{-3}\right)\end{array}$ & $\begin{array}{l}\text { Avg. } \\
\text { stand } \\
\text { snow } \\
(\mathrm{cm})\end{array}$ & $\begin{array}{c}\text { Avg. } \\
\text { snow } \\
\text { penetration } \\
(\mathrm{cm})\end{array}$ \\
\hline Snowfal & 33 & 9.65 & 23.27 & 6.45 & 0.26 & 1.53 & -2.7 & 16.5 & 142.66 & 75 & 11.35 \\
\hline No snowfall day & 60 & 11.49 & 21.26 & 8.61 & 0.35 & 1.98 & -1.9 & 0 & 0 & 71 & 5.33 \\
\hline
\end{tabular}



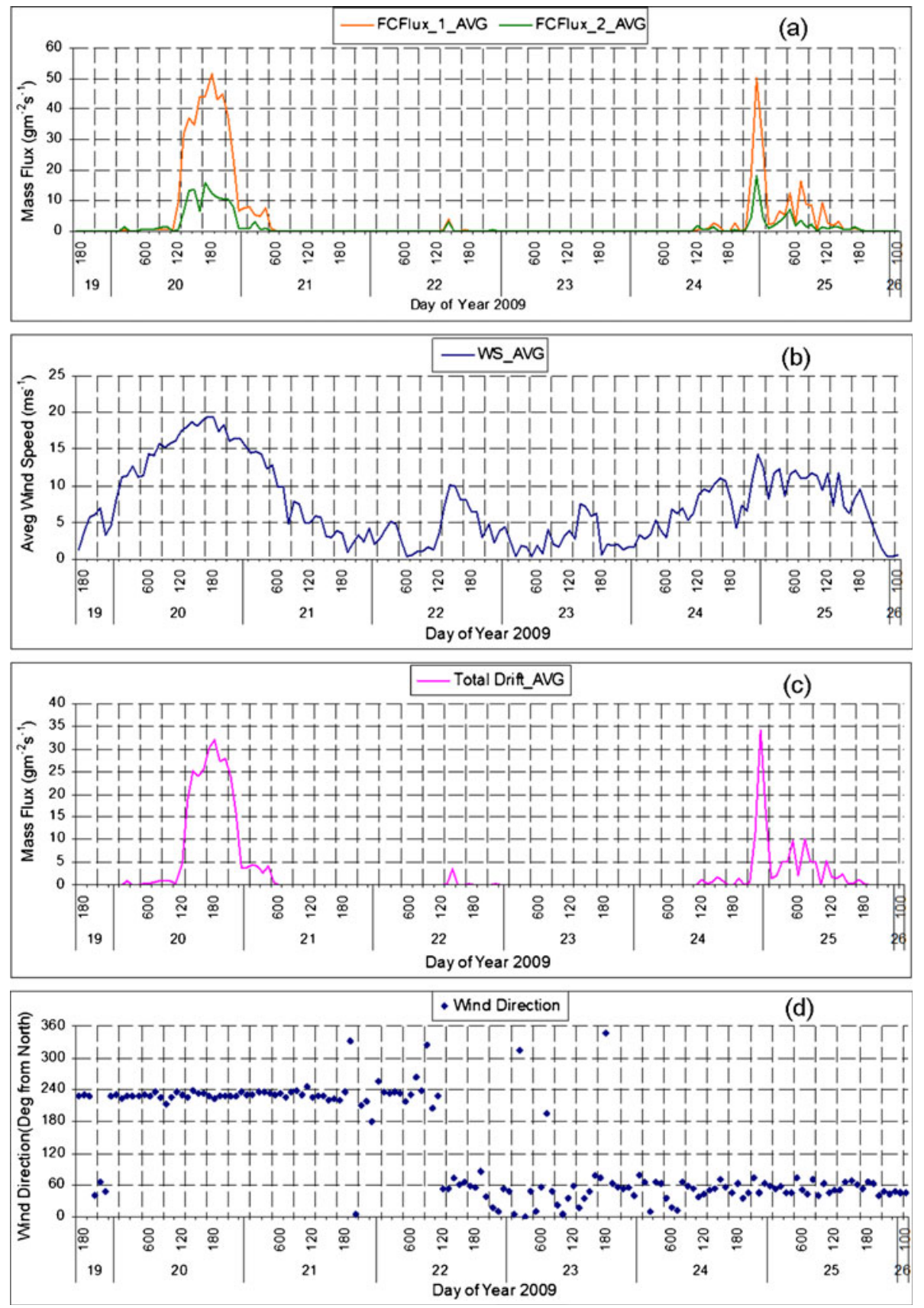

Figure 2. Wind and snowdrift recorded at D-10 Top research station between January 19 and 26, 2009. (a) Average snow mass flux as measured with lower segment (0-1 m) and upper segment (1-2 m) of FlowCapt sensor; (b) average wind speed values as measured with an RM Young propeller-vane anemometer placed at $6.0 \mathrm{~m}$ height near the FlowCapt; (c) average of snow mass flux measured with both segments of the FlowCapt sensor and (d) average wind direction values measured with an RM Young propeller-vane anemometer.

2009). The free fall ram penetrability of the snow surface was recorded as shown in figure 4 . No significant snowdrift was recorded by the FlowCapt between 21 and 24 January for an average wind speed of $3.71 \mathrm{~ms}^{-1}$. The second snowdrift event started around $1000 \mathrm{hrs}$ on 24 January and was accompanied by new snow storm. The average wind speed during this period was observed to be $9.53 \mathrm{~ms}^{-1}$ from the north-east direction. It was observed that the slope loaded during the first snowdrift activity was eroded during the second activity due to reversal of wind direction.

\subsection{Wind speed and wind direction}

The average wind speed measured with the propeller-vane anemometer of the AWS during the two drift events was $11.97 \mathrm{~ms}^{-1}$ with maximum gusts recorded up to $19.56 \mathrm{~ms}^{-1}$. The mass flux 
can be compared with the wind speed variations shown in figure 2(b). The wind speed data showed that most of the drift started above approximately $7.64 \mathrm{~ms}^{-1}$. This is the threshold wind speed, $u_{\mathrm{th}}$, at which snow particles rise up from the surface due to turbulent eddies of wind (McClung and Schaerer 1993) and is an important parameter for the calculation of snow mobility index. The snow mobility index is an indicator of occurrence of snow transport and has a zero value for the threshold wind velocity (Guyomarc'h and Mérindol 1998).

It can be observed from figure 2(d) that the wind is blowing mostly from the south-west (1st drift event) and from the north-east (2nd drift event) directions. This is because the area has a geography that makes it a kind of natural wind tunnel.

\subsection{Friction velocities and threshold friction velocity}

The friction velocity, $u_{*}$, is a measure of the wind drag force on the snow surface. Assuming neutral conditions in a boundary layer with constant fluxes, the measured wind velocities $u$ at the height

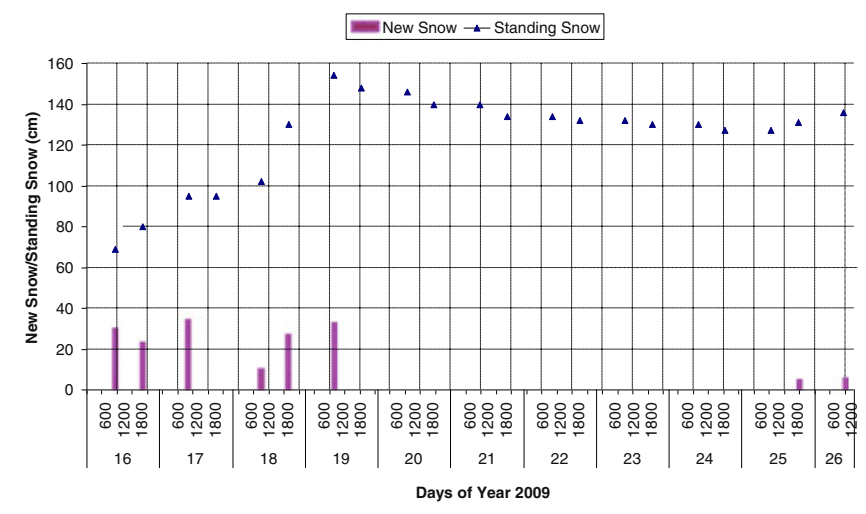

Figure 3. Standing snow and new snow during study period at observatory.

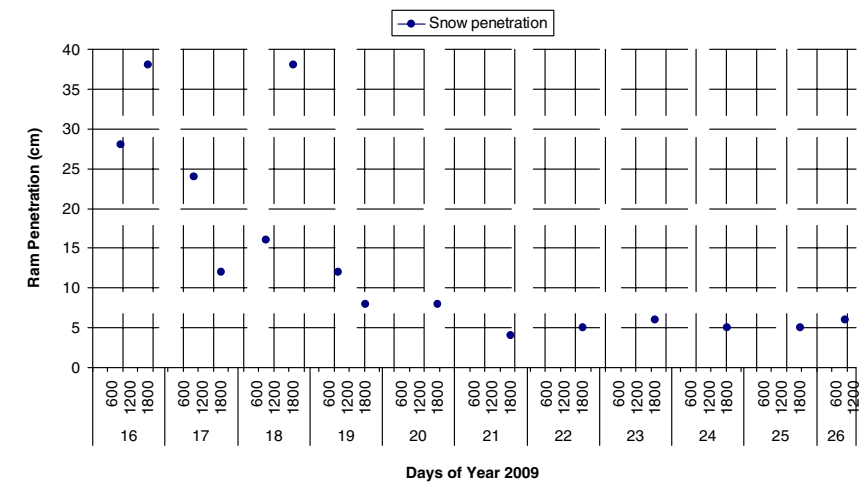

Figure 4. Penetrability of snow surface during study period at observatory. $z$ above the ground can be used to calculate iteratively the friction velocities $u_{*}$ from the following equation:

$$
u_{*}=u \frac{\kappa}{\ln \left(z / z_{0}\right)},
$$

where $\kappa$ is the Von Karman constant (0.4), the roughness length $z_{0}$ increases with the intensity of the snowdrift flux and is proportional to the height of the saltation layer (Jaedicke 2002). For the calculation of friction velocities using equation (1), the value of surface roughness $z_{0}$ is taken as $2.3 \times 10^{-4} \mathrm{~m}$, which is appropriate for seasonal snow cover (Kondo and Yamazawa 1986).

Figure 5 shows the total mass flux per unit width or total drift-snow transport rate $\left(\mathrm{Q}_{2.0}\right.$ in $\left.\mathrm{gm}^{-1} \mathrm{~s}^{-1}\right)$ plotted against friction velocities. $\mathrm{Q}_{2.0}$ is calculated by multiplying the integrated (lower and upper segments) mass flux ( $\mathrm{Q}$ in $\mathrm{gm}^{-2} \mathrm{~s}^{-1}$ ) by the height (in m) of the instrument (Jaedicke 2001).

In terms of friction velocities, the snow starts moving when a threshold friction velocity, $u_{* \mathrm{th}}$, is reached. The threshold friction velocity, $u_{* \text { th }}$ is given by (Durand et al. 2005):

$$
u_{* \operatorname{th}}=u_{\mathrm{th}} \frac{u_{*}}{u},
$$

where $u_{\mathrm{th}}$ is the threshold wind velocity at which snowdrift starts.

In connection with friction velocities measured during the experimental period using the propellervane anemometer, the threshold friction velocity, $u_{* \text { th }}$ was calculated using equation (2). Following the guidance from Bagnold (1941), $u_{* \text { th }}$ was observed when the drifts had stopped. The wind speed data for such cases were filtered and associated with the corresponding friction velocities. The average threshold value of $u_{*}$ was found to be about $0.31 \mathrm{~ms}^{-1}$. It can be observed in figure 5 that drifting of snow increases dramatically once $u_{*}$ reaches $0.31 \mathrm{~ms}^{-1}$.

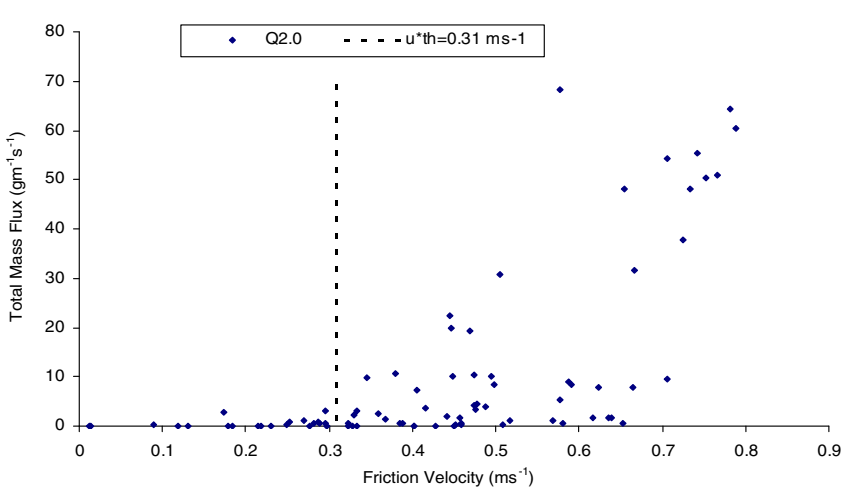

Figure 5. Total mass flux $\left(\mathrm{Q}_{2.0}\right)$ plotted against friction velocities $\left(u_{*}\right)$. 


\subsection{Saltation height}

The saltation height is the thickness of the saltation layer in which snow particles ejected from the surface rebound and eject other snow particles after traveling a curved trajectory under the influence of wind and gravity forces. The saltation height, $h$, is calculated using Greely and Iversen's (1985) formulation:

$$
h=1.6 \frac{u_{*}^{2}}{2 g},
$$

where $u_{*}$ is the friction velocity and $g$ is the gravitational acceleration.

It can be observed from the graph of figure 2(a) that the lower segment $(0-1 \mathrm{~m})$ of the FlowCapt has recorded higher values of snow mass flux indicating that larger amount of snow mass transportation has taken place between 0 and $1 \mathrm{~m}$. The saltation height was calculated using equation (3) and plotted against mass flux of lower segment in figure 6. It can be observed that saltation has taken place mostly approximately up to $6.0 \mathrm{~cm}$.

\subsection{Total snow mass transport}

The snowdrift data from the FlowCapt were used to roughly quantify the transported snow mass in the given period. Wind was blowing mostly from south-west direction in the first drift event and from north-east direction in the second drift event, thus transporting large quantities of snow. The net mass of transported snow was observed in the north-east direction.

To calculate the total mass transportation, the total mass flux (per unit width) is multiplied with the effective width of the ridge where the wind speed and the wind direction were observed to be representational. This was verified with field observations and was observed to be approximately $60 \mathrm{~m}$. This gives the total amount of snow mass transported through the entire cross-section during

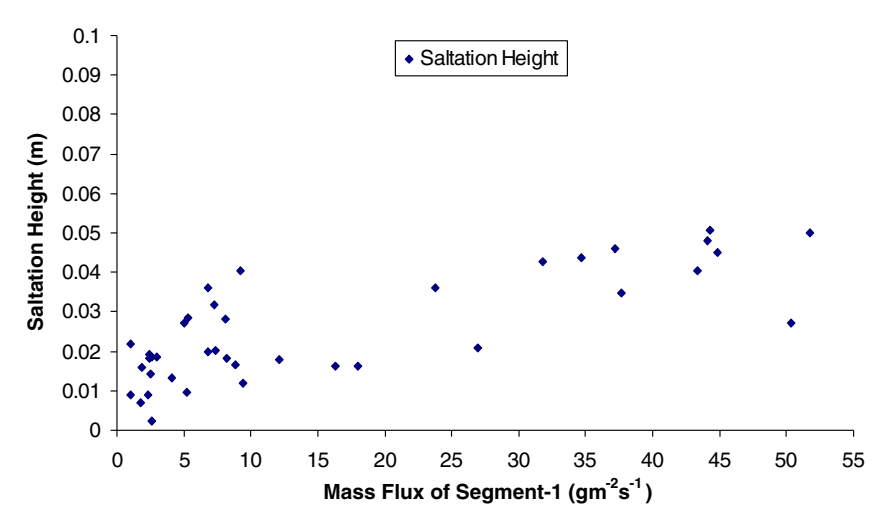

Figure 6. Saltation height $(h)$ plotted against mass flux of lower segment of FlowCapt. the study period and was found to be $66.30 \times 10^{3} \mathrm{~kg}$. This demonstrates the applicability of the instrument in providing valuable data for large-scale snow mass deposition in avalanche release zones.

The flux measurements made by the FlowCapt were compared with the empirical relations given by Takeuchi (1980) for two types of seasonal snow. Takeuchi had derived the following two expressions for old firm snow and settled dry snow, respectively:

$$
\begin{gathered}
\mathrm{Q}_{2.0}=0.2\left(U_{1}\right)^{2.7}, \quad(\text { old firm snow }), \quad(4) \\
\mathrm{Q}_{2.0}=2.9 \times 10^{-3}\left(U_{1}\right)^{4.16}, \quad(\text { settled dry snow }),
\end{gathered}
$$

where $\mathrm{Q}_{2.0}$ is the total mass flux from 0.0 to $2.0 \mathrm{~m}$ with respect to snow surface and $U_{1}$ is the wind speed measured at $1.0 \mathrm{~m}$ height.

The total mass flux $\left(\mathrm{Q}_{2.0}\right)$ of 'no snowfall-day' drift events were plotted against friction velocities in figure 7 . The solid blue and red lines show empirical functions given by Takeuchi (1980) for settled dry snow and old firm snow, respectively. It can be observed that the flux measurements from the FlowCapt are lower in magnitude than the results from Takeuchi. This is confirmed from results of earlier study carried out by Jaedicke (2001).

\subsection{Riming}

Riming was observed as the major field related problem that interrupted the smooth collection of data. During the entire period from 20072010, there were some occasions when riming was observed on both the segments of the FlowCapt, as shown in figure 8 . The most severe effects of riming were observed when the propeller-vane anemometer got stuck and gave fixed readings. Though the FlowCapt still gave readings, it is possible that partial underestimation of the snowdrift might have occurred due to temporary loss of sensitivity on

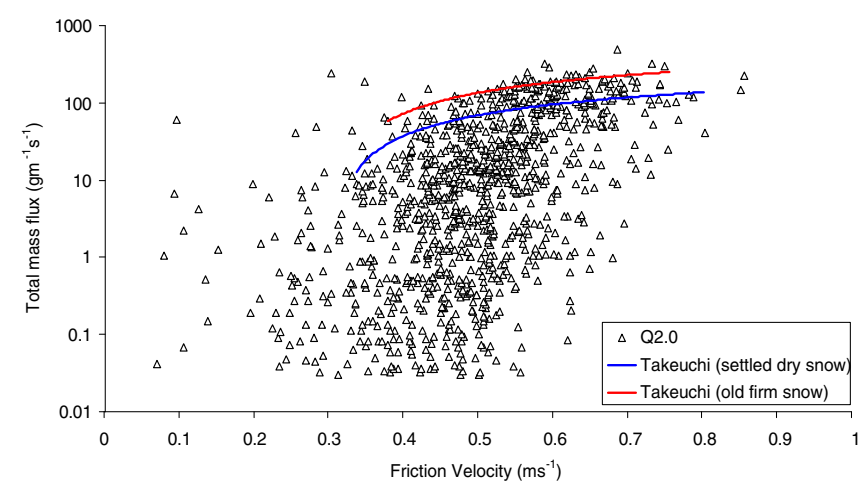

Figure 7. Comparison of total mass flux $\left(Q_{2.0}\right)$ of no snowfall-day drifts with empirical functions of Takeuchi (1980). 


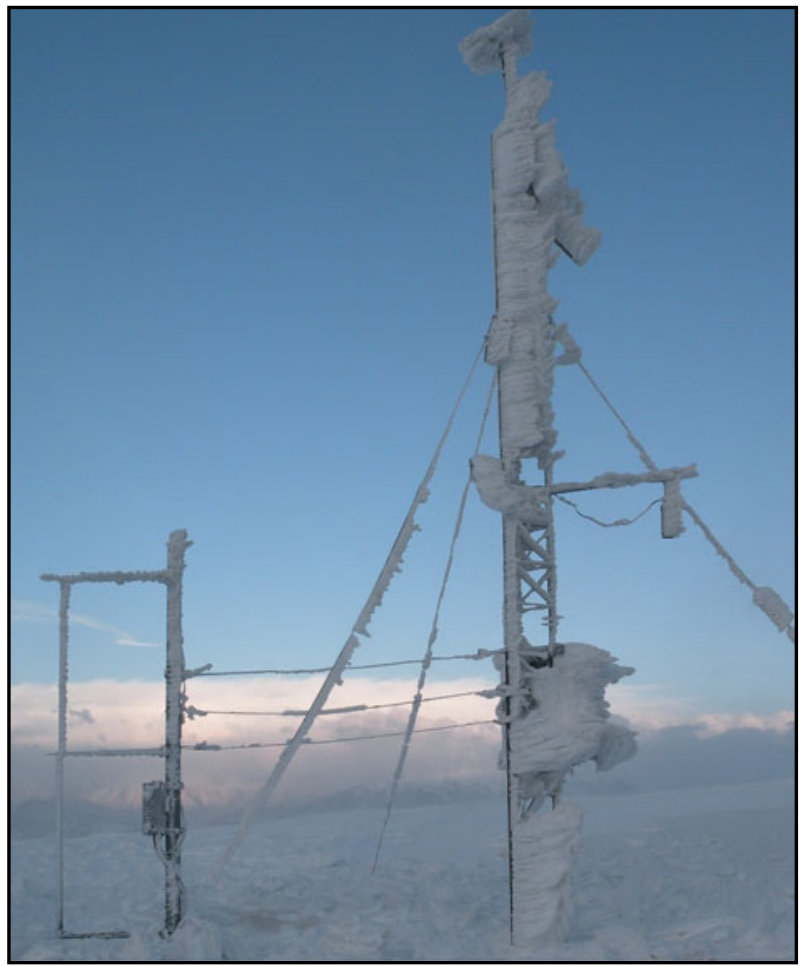

Figure 8. A photograph showing riming on the FlowCapt sensor and the Automatic Weather Station taken on 9 February 2010.

the two segments of the sensor. The formation of the ice coating around the sensor body might have resulted in the generation of vibration damping effect in the sensor. The icing was removed manually from the FlowCapt and the other snowmet sensors so as to make the AWS functional throughout the winter.

\section{Conclusion}

It has been observed that while conventional instruments used for measurement of snowdrift cannot operate successfully over long periods, the vibro-acoustic snowdrift measuring instrument can easily work autonomously over time periods up to several months in standalone mode. Maintenance in the field is reduced to a minimum, which allows extended quantitative snowdrift observations. With careful installation, the entire saltation layer can be included in the measurements, which is a major advantage as compared to optical instruments or traditional trap methods. During the study, the FlowCapt delivered data of drifting snow of different magnitudes, but in the absence of conventional snow gauges for validation, the quality of the absolute snow flux data could not be determined. The mass flux values measured with the FlowCapt instrument appeared to be lower in magnitude than previous results from Takeuchi (1980). However, with more experiments and comparison with other snow gauge readings for different snow types, algorithms may be developed for correcting this disparity.

\section{Acknowledgements}

The authors would like to thank Shri. Ashwagosha Ganju, Director, Snow \& Avalanche Study Establishment, for allowing them to carry out this research. Special thanks are due to Shri. Piyush Joshi for providing valuable guidance and Shri. S K Bhararia and Shri. R Chouhan for field assistance. The efforts made by Dr M R Bhutiyani and Dr J C Kapil in improving the quality of the manuscript are also acknowledged.

\section{References}

Bagnold R A 1941 The Physics of Blown Sand and Desert Dunes, Methuen and Company, London, pp. 255-256.

Bolognesi R 1996 The driftometer; In: Proc. International Snow Science Workshop, Banff, Canada, pp. 129-133.

Brun E, David P, Sudul M and Brunot G 1992 A numerical model to simulate snow-cover stratigraphy for operational avalanche forecasting; J. Glaciol. 38(128) 13-22.

Chritin V and Gubler H 2005 FlowCapt Nivo-meteorological Stations - Users instructions IAV Engineering, Lausanne, Switzerland, 10p.

Chritin V, Bolognesi R and Gubler H 1999 FlowCapt: A new acoustic sensor to measure snowdrift and wind velocity for avalanche forecasting; Cold Reg. Sci. Technol. 30 $125-133$.

Durand Y, Guyomarc'h G, Mérindol L and Corripio J G 2005 Improvement of a numerical snowdrift model and field validation; Cold Reg. Sci. Technol. 43 93-103.

Greely R and Iversen J D 1985 Wind as a geological process on Earth, Mars, Venus and Titan (Cambridge: Cambridge University Press), pp. 95-96.

Gubler H 1981 An electronic remote snow drift gauge; J. Glaciol. 27 164-174.

Guyomarc'h G and Mérindol L 1998 Validation of an application for forecasting blowing snow; Ann. Glaciol. 26 $138-143$.

Jaedicke C 2001 Acoustic snowdrift measurements: Experiences from the FlowCapt instrument; Cold Reg. Sci. Technol. 32 71-81.

Jaedicke C 2002 Snow drift losses from an Arctic catchment on Spitsbergen: An additional process in the water balance; Cold Reg. Sci. Technol. 34 1-10.

Kondo J and Yamazawa H 1986 Bulk transfer coefficient over a snow surface; Bound.-Layer. Meteorol. 34 123-135.

Li L and Pomeroy J W 1997 Estimates of threshold wind speeds for snow transport using meteorological data; J. Appl. Meteorol. 36 205-213.

Lieberherr G 2010 Modeling snow drift in the turbulent boundary layer, MSc Thesis, Laboratory of Environmental Fluid Mechanics, EPFL Lausanne.

McClung D and Schaerer P 1993 The Avalanche Handbook, The Mountaineers, Seattle, WA, pp. 34-35. 
Mellor M 1960 Gauging Antarctic drift snow; In: Antarctic Meteorology, Pergamon, Oxford, pp. 347-354.

Pomeroy J W and Gray D M 1990 The saltation of snow; Water Resour. Res. 26 1583-1594.

SASE Annual technical report 2009 Snow \& Avalanche Study Establishment, Chandigarh, India.

Schmidt R A 1977 A system that measures blowing snow; US Forest Service Research Paper no. RM-194, US Department of Agriculture, Fort Collins, pp. 8-17.

Schmidt R A, Meister R and Gubler H 1984 Comparison of snow drifting measurements at an Alpine ridge crest; Cold Reg. Sci. Technol. 9 131-141.
Sharma S S and Ganju A 2000 Complexities of avalanche forecasting in Western Himalaya - an overview; Cold Reg. Sci. Technol. 31 95-102.

Shiotani M and Arai H 1967 On the vertical distribution of blowing snow; In: Physics of Snow and Ice (ed.) Oura $\mathrm{H}$, International Conference on Low Temperature Science, Institute of Low Temperature Science, Hokkaido University, pp. 1075-1083.

Sommerfeld R and Businger J A 1965 The density profile of blown snow; J. Geophys. Res. 70 3303-3306.

Takeuchi M 1980 Vertical profile and horizontal increase of drift snow transport; J. Glaciol. 26 481-492.

MS received 14 September 2011; revised 27 April 2012; accepted 30 April 2012 